\title{
Transparency and Product Variety
}

Schultz, Christian

Publication date:

2007

Document version

Publisher's PDF, also known as Version of record

Citation for published version (APA):

Schultz, C. (2007). Transparency and Product Variety. Centre for Industrial Economics, Department of Economics, University of Copenhagen. 


\title{
Centre for Industrial Economics Discussion Papers
}

\author{
2007-13
}

Transparency and Product Variety

Christian Schultz

Centre for I ndustrial Economics Department of Economics, University of Copenhagen http: //www.econ.ku.dk/ClE/ 


\title{
Transparency and Product Variety*
}

\author{
Christian Schultz ${ }^{\dagger}$
}

November 2007

\begin{abstract}
We study the long run effects of transparency in a circular town model of a differentiated market. The market is not fully transparent on the consumer side: A fraction of consumers are uninformed about prices. Increasing transparency reduces the equilibrium price, profit and entry of firms. This improves welfare. If consumers' transportation cost is high, it also improves the average utility of consumers. When transportation costs are very small, the fully transparent market features cut throat competition if there are several firms in the market, and if firms choose pure entry strategies only one firm enters and acts like a monopolist. Consumers therefore prefer that market transparency is as high as possible under the restriction that the market should allow entry for two firms. If firms choose mixed entry strategies, consumers prefer full transparency.

Keywords: Market transparency, product differentiation, product variety, competition policy
\end{abstract}

JEL: L13, L15, L40

\section{Introduction}

The advent of the internet and the price-comparison sites has reinvigorated the interest in understanding how consumers' information about prices the transparency of the market on the consumer side - affects market outcomes. This paper focusses on the long run effects of transparency on the consumer side when goods are horizontally differentiated. In the long run, transparency may influence product variety, as firms' decisions to enter markets depend on the competitive environment. This raises the issues whether transparency promotes product variety, and whether it is good or bad for consumers and general welfare. These issues are considered in a circular town model of a differentiated market with costly entry as in Salop (1979).

\footnotetext{
*I am gratefull to participants in Centre for Industrial Economics' workshop 2007 for comments and suggestions.

${ }^{\dagger}$ Department of Economics, University of Copenhagen, Studiestraede 6, DK 1455 Copenhagen K. cs@econ.ku.dk, www.econ.ku.dk/CSchultz
} 
We identify market transparency with the fraction of consumers who are informed about prices - following the lead of Varian (1980). In equilibrium, uninformed consumers have correct expectations about prices, still they play an important role, since firms know that these consumers rely on expectations and not actual knowledge of prices; and this affects the demand elasticity when firms contemplate different prices.

Increasing market transparency increases firms' demand elasticities and thus intensifies competition, so that prices and profits are lowered, this benefits consumers. But it also reduces entry into the market, which lowers the number of varieties offered and reduces competition, this hurts consumers. On balance, however, if the transportation cost is sufficiently high, i.e. consumers are picky in their preferences on product variety, the effect of the intensified competition dominates, and average consumer welfare is increased. Total welfare is also increased as the total entry costs are reduced as well.

When the transportation cost is low, i.e. consumers are less picky; there is no pure strategy equilibrium to the firms' pricing game. A complete characterization of the equilibrium for all transportation cost levels has not been obtained, but results can be obtained when the consumers' transportation cost approaches zero, so the situation approaches the homogeneous market. In this case, competition becomes very intense under full transparency, and if firms choose pure entry strategies, only one firm will enter in equilibrium. For the social planner, this is optimal, transportation costs are approximately zero and the fixed entry cost is not doubled. For consumers the situation differs: As long as there are more firms in the market, an increase in transparency is pro-competitive and leads to lower prices, benefiting the consumers. But the fully transparent market features only one firm entering, and this firm chooses the monopoly price. When firms choose pure entry strategies, consumers' most preferred level of transparency exactly allows two firms to enter the market in equilibrium.

As discussed by Dixit and Stigler (1986) one may discuss whether pure strategy or mixed strategy equilibria are most reasonable for entry games. As is well known, see e.g. Andersson and Enger (2007), mixed strategy equilibria in entry games do not allow closed form solutions when there are many firms. Rather than relying on numerical simulations, I consider the case where two firms choose a mixed entry strategy. In the symmetric equilibrium, more transparency leads to less expected entry but also lower prices when two firms happen to enter. The consumers' preferred level of transparency trades off these two effects and as it turns out, the price effect is most important and consumers prefer full transparency.

Transparency and product differentiation has been touched upon before. Most closely related to the present paper is Schultz (2004) where I study the effect on product differentiation in a Hotelling model with two firms, where uninformed consumers are uninformed about prices as well as firms' 
locations. It is shown that increasing transparency reduces product differentiation and is welfare improving. Various other models consider firms' location choices in environments of imperfect consumer information, see for instance Stahl (1982), Wolinsky (1984), Dudey (1990), Fischer and Harrington (1996), Bester (1998). These papers do not consider the decision to enter the market. Another group of papers consider choice of price and quality when consumers have imperfect information, see Chan and Leland (1982), Dranove and Satterthwaite, (1992) and Armstrong and Chen (2007). Boone and Potters (2002) consider the case where some consumers are unaware of all existing products. In the present paper, transparency is an exogenous feature of the model, a literature has studied the case where information about prices and products are provided through advertising by the firms (among others Butters (1977), Grossman-Shapiro (1984), and Bester and Petrakis (1995)). More transparency on the producer side is typically seen as anti-competitive as it facilitates collusion, see Kuhn and Vives (1995). Schultz (2005) shows that transparency on the consumer side makes tacit collusion harder.

\section{The model}

We consider a differentiated market a la Salop (1979) where consumers and firms are located on a circle with circumference one. A large number of potential firms with outside opportunity zero can enter the market at a cost of $f$. Firms in the market are located equidistantly. There is a continuum of consumers. A consumer buys at most one unit of the (differentiated) good. If she buys at the price $p$ from a firm, located $x$ away from her, her utility is

$$
V=u-p-t x,
$$

where $u>0$ is the reservation price, and the parameter $t>0$ is the transportation cost, reflecting the "pickiness" of the consumer. With $n$ firms in the market, the distance between two neighboring firms is $1 / n$. A consumer located between firms $i$ and $j$ is indifferent between buying from the firms, if she her distance to $i$ is

$$
x\left(p_{i}, p_{j}\right)=\frac{1}{2 n}+\frac{p_{j}-p_{i}}{2 t} .
$$

There are two information types of consumers: only a fraction, $\phi$, is informed about the firms' prices. This is common knowledge, and thus known by the firms. The parameter $\phi$ is our measure of transparency. Both information types are uniformly distributed on the circle. Consumers know firms' locations.

An uninformed consumer expects firm $i^{\prime} s$ price to be $p_{i}^{e}$. She can only visit one firm, and can therefore not learn all prices by visiting all firms before 
purchase. If the distance to firm $i$ is $x$, the expected utility from buying from firm $i$ is $u-p_{i}^{e}-t x$. We focus on symmetric equilibria, where all firms charge the same price. This is expected by the uninformed consumers so they buy from the nearest firm. To avoid treating many different cases, we assume that the market is covered. Hence, each firm will get the demand from half of the uniformed consumers located in between it and its neighbors.

If the two firms neighboring firm $i$ charge the same price $p_{-i}$, the total demand facing firm $i$ will be

$$
D\left(p_{i}, p_{-i}, \phi, n\right)=\phi\left(\frac{1}{n}+\frac{p_{-i}-p_{i}}{t}\right)+\frac{1-\phi}{n} .
$$

The timeline is as follows: First firms decide whether to enter the market. Then firms in the market set prices, which are observed by a fraction $\phi$ of the consumers. The uninformed consumers form expectations. Consumers then decide which firm to buy from (if any). Finally transactions take place.

\section{When transportation costs are high}

First we assume that transportation costs are high, i.e. consumers are picky:

$$
t \geq \max \left[\frac{4(1-\phi)^{2} \phi}{\left(2+\phi-\phi^{2}\right)^{2}} \frac{u^{2}}{f}, 4 f \phi\right] .
$$

As will be clear, the first condition ensures that the firms' price strategies are pure and the second that at least two firms enter the market. ${ }^{1}$.

We solve the model backwards (for perfect Bayesian equilibria). When $n$ firms have entered, each firm maximizes (gross) profit, $\pi_{i}$, given other firms' prices, $p_{-i}$. For simplicity, we assume that marginal costs are constant and normalize them to zero. Firm $i^{\prime} s$ problem is

$$
\max _{p_{i}} \pi_{i}=\max _{p_{i}} p_{i} D\left(p_{i}, p_{-i}, \phi, n\right) .
$$

In a symmetric equilibrium $p_{i}=p_{-i}$, and the equilibrium price and gross profit fulfil

$$
p(\phi, n)=\frac{t}{\phi n} ; \pi(\phi, n)=\frac{t}{\phi n^{2}} .
$$

More firms and higher transparency give lower equilibrium price and profit.

First, we consider pure entry strategies. Then the number of firms is determined such that the gross profit equals the entry cost $f$. Hence, the

\footnotetext{
${ }^{1}$ The term $\frac{4(1-\phi)^{2} \phi}{\left(2+\phi-\phi^{2}\right)^{2}}$ is bell shaped, equal to 0 at $\phi=0$ and at $\phi=1$, and its $\max$ value is 0.12 .
} 
equilibrium number of firms $n^{*}(\phi)$ is ${ }^{2}$

$$
n^{*}(\phi)=\sqrt{\frac{t}{\phi f}} .
$$

An increase in transparency reduces profitability and fewer firms enter. The solution is only valid, if at least two firms are in the market, $\left(n^{*}(\phi) \geq 2\right)$, which requires that the second part of (2) is fulfilled.

If the transportation cost is low, this equilibrium may not be viable, since the equilibrium profit is low, and it may be a better option for a firm to charge a high price $u-\frac{t}{2 n}$ and only sell to the uninformed consumers arriving in equilibrium ${ }^{3}$. Hence, the equilibrium is only valid if $\frac{t}{\phi n^{2}} \geq \frac{1-\phi}{n}\left(u-\frac{t}{2 n}\right)$. Inserting $n^{*}(\phi)$ gives the first part of (2).

The equilibrium price at the equilibrium number of firms is

$$
p^{*}(\phi)=p\left(\phi, n^{*}(\phi)\right)=\sqrt{\frac{t f}{\phi}},
$$

which is clearly decreasing in $\phi$. Thus increasing transparency lowers the price even when the effects on product variety and the number of firms are taken into account.

A social planner would prefer a number of firms, which minimizes the sum of entry costs and transportation costs:

$$
\min _{n} n f+2 n \int_{0}^{\frac{1}{2 n}} t x d x
$$

which gives

$$
n^{s}=\frac{1}{2} \sqrt{\frac{t}{f}}
$$

As $\phi \leq 1$ this is less than the number of firms entering the market in the decentralized solution. As an increase in transparency decreases entry it benefits the social planner. He thus prefers full transparency, $\phi^{s}=1$.

Increasing transparency affects consumers through two channels: They gain since prices are lowered, but are hurt by higher transportation costs since fewer firms enter. The net effect on consumers' average utility, $\bar{V}$,

\footnotetext{
${ }^{2}$ To be precise, the number of firms entering the market is the integer part of $\sqrt{t /(\phi f)}$. For ease of notation, we disregard integer problems, when no confusion is possible.

${ }^{3}$ We assume that transportation cost is not sunk when an uninformed consumer visits a firm (so a geographical interpretation of the model is not valid). Hence the consumer in the middle buys iff $u-t / 2 n$. It is easy to check that it is not better for firms to charge an even higher price than $u-t / 2 n$.
} 
from an increase in transparency is (using (1))

$$
\frac{\partial \bar{V}}{\partial \phi}=-\frac{\partial p}{\partial \phi}-\frac{\partial\left(2 n(\phi) \int_{0}^{\frac{1}{2 n(\phi)}} t x d x\right)}{\partial \phi}=\left(\frac{1}{2 \phi}-\frac{1}{8}\right) \frac{t}{\phi \sqrt{\left(\frac{t}{\phi f}\right)}}>0,
$$

as $\phi<1$. Hence, consumers' average utility increases with transparency. As the firms are moving around on the circle when the number changes (they are located equidistantly) a change in transparency is not necessarily Pareto better.

\section{The almost homogeneous market}

When consumers are not picky, (transportation costs are low), the first part of (2) is not fulfilled and there is no pure strategy equilibrium to the firms' pricing game. As shown by Varian (1980) for a homogeneous market, the equilibrium then involves mixed strategies at the pricing stage. Schultz (2005) characterizes the symmetric mixed strategy equilibrium in a Hotelling model, where two firms are located at the end of the interval $[0,1]$. The characterization does not allow closed form solutions, but it is shown (in Lemma 1) that in the limit as the transport cost $t$ tends to zero, the expected profit of each firm approaches $(1-\phi) u / 2$. This is the expected profit from selling at the monopoly price to the uninformed consumers only and sharing the market. This was also shown by Varian for the homogeneous market. ${ }^{4}$ A straightforward adaption of the proof of Lemma 1 in Schultz (2005) shows that this also holds when $n$ firms share the market as here. Therefore the expected profit of the firms in the symmetric mixed strategy equilibrium with $n$ firms approaches,

$$
E \pi_{0}(n)=\frac{1-\phi}{n} u
$$

as $t \rightarrow 0$. The result is intuitive: It is always an option for a firm to charge the reservation price, which equals $u$ when transportation costs vanish, and only serve the uninformed consumers arriving. In a mixed strategy equilibrium, each price in the support of the distribution must give same expected profit, and hence the expected profit is given by (5).

When $n \geq 2$, the equilibrium number of firms, $n^{0}(\phi)$, is determined by the condition that expected gross profits equal the entry cost, therefore ${ }^{5}$

$$
n^{0}(\phi)=(1-\phi) \frac{u}{f} \text {. }
$$

\footnotetext{
${ }^{4}$ See Kühn and Rimler (2007) for a more general analysis of comparative static results on tacit collusion when differentiated product markets approach homogeneous markets.

${ }^{5}$ Again we ignore integer problems.
} 
The number of firms is decreasing in transparency. This solution is only valid if $n^{0}(\phi) \geq 2$. If $n^{0}(\phi)<2$ there is no equilibrium, where firms choose pure entry strategies and more than one firm enters. If $u>f$, an equilibrium with pure entry strategies exist in which a single firm enters, becomes monopolist and charge $u$ to all consumers. If $f>u$, the market is not viable.

In the limiting homogeneous market, the social planner prefers exactly one firm, hence if

$$
n^{0}(\phi)=(1-\phi) \frac{u}{f} \geq 2 \text { and } u>f
$$

an increase in transparency is preferred by the social planner.

For consumers the situation is different. In the fully transparent market, there is one firm charging the monopoly price $u$. When the market is not fully transparent a firm's expected profit is given by (5) and the total expected profit is $(1-\phi) u$. The total sale equals one, so the expected price is $p^{e}=$ $(1-\phi) u<u$. This is independent of the number of firms! Accordingly, consumers prefer an increase in transparency as long as this leads to more than one firm. The optimal degree of transparency for the consumers fulfils $n^{0}(\phi)=2$, i.e.

$$
\phi^{c}=1-2 \frac{f}{u} .
$$

So, the consumers do not prefer full transparency.

\section{$5 \quad$ Mixed strategies at the entry stage}

As noted by Dixit and Shapiro (1986), one can discuss whether pure strategy or mixed strategies are most reasonable in entry games. In this section, therefore, we solve for a mixed strategy equilibrium at the entry stage. With many firms closed solutions are not available, as the expected profit from entering includes a binomial term, when many firms are mixing, see Dixit and Shapiro (1986), Vettas (2006) and Anderson and Enger (2007). Rather than resorting to numerical solutions, we consider the case of two potential entrants playing the same mixed strategy. (An interpretation is that the other potential entrants have chosen the pure strategy to stay out).

If the other firm chooses to enter with probability $\mu$, firm $i^{\prime} s$ expected profit from entering is

$$
(1-\mu) u+\mu \frac{1-\phi}{2} u-f .
$$

In equilibrium this equals the payoff from staying out, 0 , which implies

$$
\mu=2 \frac{u-f}{u(1+\phi)},
$$


from which we see that the entry probability is decreasing in transparency. From the consumers' point of view this feature of increasing transparency is bad. On the other hand, increasing transparency decreases the price when both firms enter, which is good. A consumer's expected utility is

$$
\mu^{2}(u-((1-\phi) u))+2(1-\mu) \mu(u-u)+(1-\mu)^{2} 0=\mu^{2} \phi u .
$$

And the consumers' preferred level of transparency is therefore, $\phi^{c m}=1$.

Hence, consumers prefer a fully transparent market, even though it gives the lowest possible probability for two firms entering the market.

The social planner trades off the probability of having too much entry, such that entry costs are doubled, with the probability of having no entry, such that no surplus is generated in the market. His utility is

$$
\mu^{2}(u-2 f)+2(1-\mu) \mu(u-f)+(1-\mu)^{2} 0 .
$$

Maximizing with respect to $\phi$ yields $\phi^{s}=1$. Hence, the social planner still prefers full transparency when firms choose a mixed entry strategy.

\section{Concluding remarks}

Transparency on the consumer side affects the competitiveness of a market. In this paper we have shown that when one accounts for the long run effects on product variety and entry, full transparency is always welfare maximizing. Consumers like high transparency as it makes the market more competitive. This reduces product variety, and as long as there are more than one firm in the market - or firms play mixed entry strategies- consumers prefer more transparency to less. If firms choose pure entry strategies, there is an optimal level of transparency for consumers, which exactly allows two firms to enter.

\section{References}

[1] Andersson, S. and M. Engers (2007), Participation Games: Market Entry, Coordination, and the Beautiful Blonde, Journal of Economic Behavior and Organization, 63(1), 120-137, May

[2] Armstrong, M. and Chen Y. (2007), Inattentive Consumers and Product Quality, mimeo, University College London

[3] Bester, H. (1998), Quality uncertainty mitigates product differentiation, RAND Journal of Economics, 29(4), 828-844

[4] Bester, H. and E. Petrakis (1995), Price Competition and Advertising in Oligopoly, European Economic Review, 39, 1075-1088 
[5] Boone, J. and J.J.M. Potters (2002), Transparency, prices and welfare with imperfect substitutes, CentER, wp 2002-07

[6] Chan Y.-S., and H. Leland (1982): "Prices and Qualities in Markets with Costly Information," Review of Economic Studies, 49(4), 499-516

[7] Dixit, A. and Shapiro, C. (1986), Entry dynamics with mixed strategies. In: Thomas III, L.G. (Ed.), The Economics of Strategic Planning: Essays in Honor of Joel Dean. Lexington Books, Lexington, MA, 63-79

[8] Dranove, D., and M. Satterthwaite, (1992): "Monopolistic Competition When Price and Quality are Imperfectly Observable," Rand Journal of Economics, 23(4), 518-534.

[9] Dudey, M. (1990), Competition by Choice: The Effect of Consumer Search on Firm Location Decisions, American Economic Review, 80 (5), 1092-1104

[10] Fischer, J.H. and J.E. Harrington Jr. (1996), Product Variety and Firm Agglomeration, RAND Journal of Economics, 27(2), 281-309

[11] Kühn, K-U. and X. Vives, (1995), Information Exchanges among Firms and their Impact on Competition, Office for Official Publications of the European Communities, Luxemburg

[12] Kühn, K-U.and M.S. Rimler (2007), The comparative statics of collusion models, Working Paper, University of Michigan

[13] Salop, S.C. (1979), Monopolistic Competition with Outside Goods, The Bell Journal of Economics, 141-156

[14] Schultz, C. (2004), Market Transparency and Product Differentiation, Economics Letters, 83, 173-178

[15] Schultz, C. (2005), Transparency on the Consumer Side and Tacit Collusion, European Economic Review, 49(2), February, 279-297

[16] Stahl, K. (1982), Differentiated Producs, Consumer Search and Locational Oligopoly, Journal of Industrial Economics, 31, 97-113

[17] Varian, H. (1980), A Model of Sales, American Economic Review, 70(4), 651-59.

[18] Vettas, N. (2000), On entry, exit, and coordination with mixed strategies, European Economic Review, 44(8), August, 1557-1576

[19] Wolinsky, A. (1984), Product Differentiation with Imperfect Information, Review of Economic Studies, 51, 53-61 